\title{
Ácido indol-3-butírico (AIB) no enraizamento de estacas de fedegoso gigante
}

\author{
Bruno Oliveira Lafetá1*, Milena Pimenta de Matos ${ }^{1}$, Patrícia Lage ${ }^{1}$, Ana Carolina Ferraro¹, Tamires Mousslech Andrade Penido² \\ ${ }^{1}$ Instituto Federal de Educação, Ciência e Tecnologia de Minas Gerais, Av. Primeiro de Junho, 1043, Centro, CEP 39705-000, São João Evangelista, MG, Brasil \\ ${ }^{2}$ Universidade Federal dos Vales do Jequitinhonha e Mucuri, Rod. MGT 367, Km 583, 5000, Alto Jacuba, CEP 39100-000, Diamantina, MG, Brasil
}

*Autor correspondente:

bruno.lafeta@ifmg.edu.br

Termos para indexação:

Herbácea

Rizogênese

Semilenhosa

Index terms:

Herbaceous

Rhizogenesis

Semihardwood

Histórico do artigo:

Recebido em 16/10/2015

Aprovado em 20/12/2016

Publicado em 30/12/2016

doi: $10.4336 / 2016 . p f b .36 .88 .1084$

\begin{abstract}
Resumo - O ácido indol-3-butírico (AIB) é um regulador vegetal amplamente empregado para induzir o enraizamento de estacas. O objetivo do presente trabalho foi avaliar o efeito de diferentes concentrações de AIB e de dois tipos de estacas na propagação vegetativa de Senna alata (Linnaeus) Roxburgh. O experimento foi estabelecido em delineamento inteiramente casualizado com quatro repetições, em esquema fatorial $4 \times 2$, sendo estudado o efeito de quatro concentrações de AIB: $\mathrm{T} 1$ - $0 \mathrm{mg} \mathrm{L}^{-1}$ (controle); T2 - $250 \mathrm{mg} \mathrm{L}^{-1}$; T3 - $500 \mathrm{mg} \mathrm{L}^{-1}$ e T4 - $1.000 \mathrm{mg} \mathrm{L}^{-1}$ e de dois tipos de estacas (E1 - herbácea e E2 - semilenhosa). Cada unidade experimental foi constituída por 12 estacas. As concentrações estudadas desse regulador vegetal não influenciaram no desenvolvimento do sistema radicular e aéreo das mudas e, por conseguinte, em sua sobrevivência em casa de sombra. Na casa de vegetação, as estacas herbáceas foram aquelas que perderam menos folhas remanescentes após redução da área foliar $(27,88 \%)$ e, consequentemente, apresentaram maior sobrevivência $(99,44 \%)$ quando foram mantidas em casa de sombra. Estacas herbáceas podem ser recomendadas para a propagação vegetativa de S. alata.
\end{abstract}

\section{Indol-3-butyric acid (IBA) in rooting of fedegoso gigante cuttings}

\begin{abstract}
Indole-3-butyric acid (IBA) is a plant growth regulator widely used to induce rooting of cuttings. The objective of this work was to evaluate the effect of different concentrations of IBA and of two cuttings types in vegetative propagation of Senna alata (Linnaeus) Roxburgh. The experiment was established in a completely randomized design with four repetitions, in factorial $4 \times 2$, using four concentrations of AIB: T1 - $0 \mathrm{mg} \mathrm{L}^{-1}$ (control); $\mathrm{T} 2-250 \mathrm{mg} \mathrm{L}^{-1}$; $\mathrm{T} 3-500 \mathrm{mg} \mathrm{L}^{-1}$ and $\mathrm{T} 4-1,000 \mathrm{mg} \mathrm{L}^{-1}$ and two cuttings types (E1 - herbaceous and E2 - semi-hardwood). Each experimental unit consisted of 12 cuttings. The studied growth regulator concentrations did not influence seedlings root and aerial systems development and, therefore, the survival in shade house. In greenhouse, herbaceous cuttings lost less remaining leaves after leaf area reduction (27.88\%) and, consequently, had higher survival $(99.44 \%)$ when were kept in shade house. Herbaceous cuttings can be recommended for vegetative propagation of $S$. alata.
\end{abstract}




\section{Introdução}

Senna alata (Linnaeus) Roxburgh (Fabaceae Caesalpinioideae), popularmente conhecida por fedegoso gigante, é uma planta perene arbustiva de rápido crescimento, cujo interesse comercial é crescente devido às suas propriedades medicinais. Pode ser usada para regular o fluxo menstrual, em tratamento de anemia e como laxante natural (Rodrigues et al., 2009; Braga et al., 2010; Medeiros et al., 2012; Ogunjobi \& Abiala, 2013; Pathak \& Chhetri, 2015). Além disso, a ação antimicrobiana de extratos obtidos com suas folhas já foi comprovada no controle de fungos e bactérias, tanto em humanos quanto em plantas (Ogunjobi \& Abiala, 2013).

Embora seja uma espécie pouco estudada, seu gênero é de ocorrência pantropical e possui mais de 260 espécies, sendo que cerca de $80 \%$ são encontradas no continente americano (Faria et al., 2013; Pathak $\&$ Chhetri, 2015). No Brasil, ocorre desde o sudeste até a região norte (Braga et al., 2010). É utilizada em projetos paisagísticos, indústrias de cosméticos e como fixadora de nitrogênio e fornecedora de sombra para o estabelecimento de plantas de estádios mais avançados de sucessão, em programas para a recuperação de áreas degradadas (Faria et al., 2013; Pathak \& Chhetri, 2015).

O tegumento das sementes de S. alata é duro e impermeável, características que dificultam absorção de água e as trocas gasosas na semente, fundamentais para a germinação. A propagação dessa espécie é realizada predominantemente por sementes, sendo recomendável a superação dessa dormência através de tratamentos prégerminativos (Braga et al., 2010). A estaquia, por sua vez, é uma alternativa à propagação seminal e se baseia na indução do enraizamento adventício de segmentos destacados de uma planta matriz, formando indivíduos idênticos à mesma (ou clones). Essa técnica permite a obtenção de um grande volume de mudas com baixo custo durante todo o ano, a redução da juvenilidade e o aumento da uniformidade e vigor da produção (Zem et al., 2015).

O enraizamento de estacas pode ser influenciado pelo balanço hormonal, condições fisiológicas e idade da planta matriz, maturação/juvenilidade dos propágulos, período de coleta de estacas, luminosidade, umidade, temperatura e tipo de estaca (Alfenas et al., 2004; Xavier et al., 2013). Ainda que a presença de folhas estimule a rizogênese através do fornecimento de produtos fotossintéticos, como hormônios e carboidratos, a deposição do excesso de água na lâmina foliar (efeito "guarda-chuva") pode prejudicar a eficiência de irrigação e causar o tombamento vegetal (Xavier et al., 2013; Correia et al., 2015). Para minimizar a transpiração e os efeitos negativos da presença de folhas em estacas, tem sido estudada a redução da lâmina foliar (Purcino et al., 2012; Moraes et al., 2014; Correia et al., 2015; Stuepp et al., 2015).

Os viveiros florestais demandam determinados insumos para a produção de mudas via estaquia que, em quantidades adequadas, podem aumentar os lucros. Reguladores vegetais são substâncias orgânicas complexas capazes de modificar processos fisiológicos e morfológicos da planta (Vilarinho \& Cândido, 2014). A formulação de uma concentração equilibrada desses reguladores tem como propósito garantir o crescimento vegetal, conforme dado padrão de qualidade.

Baixos níveis de auxinas endógenas podem limitar o enraizamento de determinadas espécies florestais, sendo recomendada a aplicação de reguladores vegetais sintéticos capazes de simular o efeito daquelas produzidas pelas plantas (Pio et al., 2006; Zem et al., 2015). O uso desses reguladores é comumente indicado em ocasiões em que há ausência de resposta rizogênica e/ou quando se deseja aumentar a homogeneidade de estacas enraizadas. Um exemplo é o ácido indol-3-butírico (AIB), auxina sintética fotoestável de ação localizada, pouco sensível à degradação biológica e amplamente usada na produção de mudas via estaquia (Mindêllo Neto et al., 2004; Alves, 2014). Este produto tem sido comercializado devido à capacidade de estimular a formação de primórdios radiculares, aumentando a porcentagem de estacas enraizadas e diminuindo o tempo de permanência em viveiro (Mindêllo Neto et al., 2004; Amaral et al., 2012).

A estaca de origem caulinar é constituída por um segmento de ramo com gemas apicais e/ou laterais, podendo apresentar consistência herbácea, lenhosa (Xavier et al., 2003) ou semilenhosa. O grau de lignificação aumenta no sentido da consistência herbácea para a lenhosa, sendo que as estacas herbáceas apresentam maior potencial meristemático para o enraizamento (Xavier et al., 2013). Por outro lado, há relatos que estacas mais lignificadas e espessas apresentam elevadas quantidades de assimilados que permitem a formação de raízes em ambientes menos luminosos (Vilarinho \& Cândido, 2014). Enfatiza-se que a escolha inadequada do tipo de estaca pode resultar em taxas elevadas de mortalidade, inviabilizando a produção de mudas (Santos et al., 2014). 
Diante da carência de estudos sobre a propagação via estaquia de espécies florestais nativas (Dias et al., 2012b, 2015; Xavier et al., 2013), especialmente de S. alata, as seguintes hipóteses foram testadas: I - há algum tipo de interação entre o AIB e o tipo de estaca de S. alata?; II - a propagação via estaquia pode ser recomendada para a espécie estudada? Frente a essas hipóteses, o objetivo do presente trabalho foi avaliar o efeito de diferentes concentrações de ácido indol-3-butírico (AIB) e de dois tipos de estacas na propagação vegetativa de $S$. alata.

\section{Material e métodos}

O trabalho foi realizado em área do Instituto Federal de Educação, Ciência e Tecnologia de Minas Gerais - Campus São João Evangelista (IFMG/SJE). O clima regional, classificado pelo sistema internacional de Köppen, é do tipo Cwa, temperado chuvosomesotérmico (inverno seco e verão chuvoso), com médias anuais de temperatura e precipitação de $21^{\circ} \mathrm{C}$ e $1.400 \mathrm{~mm}$, respectivamente (Braga et al., 1999).

Coletaram-se estacas herbáceas e semilenhosas no terço inferior da parte aérea de mudas e árvores de Senna alata em 17 de março de 2014. Esta posição em relação à copa foi escolhida com a finalidade de melhorar a capacidade de enraizamento das estacas devido à maior juvenilidade e vigor dos tecidos (Wendling \& Xavier, 2001). Os indivíduos doadores de estacas não apresentavam sinais aparentes de injúrias ocasionadas pelo ataque de insetos ou doenças. Definiu-se como estacas herbáceas aquelas coletadas em 20 mudas (altura de 20 a $35 \mathrm{~cm}$ e diâmetro do coleto superior a $4 \mathrm{~mm}$ ) produzidas via seminal no viveiro de espécies florestais do IFMG/SJE. No mesmo instituto, foram coletadas estacas de consistência semilenhosa de oito árvores (altura de 2,31 $\pm 0,35 \mathrm{~m}$ e diâmetro a $1,30 \mathrm{~m}$ do solo de $10,38 \pm 1,92 \mathrm{~cm})$.

A coleta de ramos para confecção das estacas foi realizada com auxílio de tesoura de poda esterilizada em fogo no início da tarde $(13 \mathrm{~h})$; horário definido conforme disponibilidade estrutural do viveiro para a instalação experimental. Os materiais propagativos foram imediatamente acondicionados em bandeja com solução de hipoclorito de sódio ( $\mathrm{NaClO}$ ), com 2, 0 a 3,0\% de cloro ativo $(\mathrm{v} / \mathrm{v})$ e, posteriormente, lavados em água corrente. O comprimento das estacas herbáceas foi de 7,79 $\pm 0,72 \mathrm{~cm}$ (diâmetro da base de 1,72 $\pm 0,64 \mathrm{~mm}$ ) e das semilenhosas de 10,28 $\pm 1,01 \mathrm{~cm}$ (diâmetro da base de 2,22 $\pm 1,30 \mathrm{~mm}$ ), cada estaca teve a área foliar reduzida a um par de folhas com dois folíolos basais apenas.

As soluções de ácido indol-3-butírico (AIB) foram preparadas dissolvendo-se o regulador vegetal, previamente calculado e pesado em balança analítica com precisão de 0,0001 g, em hidróxido de sódio $(\mathrm{NaOH})$ a $1 \mathrm{~mol} \mathrm{~L}^{-1}$, com o intuito de facilitar a posterior diluição e homogeneização em água destilada. Essa diluição em $\mathrm{NaOH}$ está de acordo com a descrição de reguladores vegetais e seus solventes apresentada por Quisen \& Angelo (2008). O delineamento experimental foi inteiramente casualizado com quatro repetições, em esquema fatorial $4 \times 2$, sendo estudado o efeito de quatro concentrações de ácido indol-3-butírico (AIB): $\mathrm{T} 1$ - $0 \mathrm{mg} \mathrm{L}^{-1}$ (controle - apenas água destilada); $\mathrm{T} 2$ - $250 \mathrm{mg} \mathrm{L}^{-1}$; T3 - $500 \mathrm{mg} \mathrm{L}^{-1} \mathrm{e} \mathrm{T} 4-1.000 \mathrm{mg} \mathrm{L}^{-1} \mathrm{e}$ dois tipos de estacas (E1 - herbácea e E2 - semilenhosa). Cada unidade experimental foi constituída por 12 estacas.

O estaqueamento foi realizado em tubetes de plástico rígido de fundo aberto (capacidade de $180 \mathrm{~cm}^{3}$, seção circular e com 8 estrias internas salientes, longitudinais e equidistantes) em sistema de canteiro suspenso. Cada tubete foi preenchido com substrato comercial composto por casca de pinus (Mecplant ${ }^{\circledR}$ - Classe A) com capacidade de retenção de água de $60,0 \%$ (p/p). Este substrato foi enriquecido com formulado de liberação controlada Osmocote $\AA$ 15-9-12 (2 $\left.\mathrm{g} \mathrm{kg}^{-1}\right)$.

A base das estacas foi imersa nas concentrações de AIB por $2 \mathrm{~s}$ e depois enterradas no substrato em profundidade média de $1,5 \mathrm{~cm}$. O tempo de imersão de estacas em reguladores vegetais foi escolhido de forma empírica dentro do intervalo adotado por diversos autores (Conover \& Poole, 1991; Tofanelli et al., 2003; PIO et al., 2004; Augusto et al., 2006; Faria et al., 2007; Peña et al., 2012; Sarmiento et al., 2015). As unidades experimentais foram mantidas em casa de vegetação com tela de sombreamento de monofilamento (malha para $50 \%$ de luminosidade) e irrigadas quatro vezes ao dia durante 5 min (vazão do bico miniaspersor de $7 \mathrm{~L} \mathrm{~h}^{-1}$ ) para conservação do turgor hídrico das estacas e indução do enraizamento. Avaliou-se aos 42 dias a frequência relativa de estacas que perderam as folhas remanescentes após redução da área foliar (PFR, \%), estacas que emitiram novas folhas (NF, \%) e estacas que emitiram novas folhas, mesmo perdendo as remanescentes (NFPF, \%). 
Em seguida, o material experimental foi transferido para aclimatação em casa de sombra (com a mesma malha da casa de vegetação) e submetido à irrigação três vezes ao dia durante $20 \mathrm{~min}$ (vazão do bico aspersor de $47 \mathrm{~L} \mathrm{~h}^{-1}$ ), onde foi mantido por 49 dias. Foi registrada a sobrevivência $(\mathrm{S}, \%)$ das estacas aos 91 dias após instalação do experimento. Aquelas que não apresentavam folhas e/ou exibiam sinais de necrose foram consideradas mortas.

As mudas obtidas foram cortadas na região do colo, próximas ao substrato, para isolamento e lavagem do sistema radicular em água corrente para retirada do substrato de cultivo. Tomaram-se os comprimentos da parte aérea $(\mathrm{PA}, \mathrm{cm})$ e da maior raiz presente no sistema radicular (SR, $\mathrm{cm}$ ) com auxílio de paquímetro digital de precisão de $0,1 \mathrm{~mm}$. O comprimento da parte aérea foi caracterizado pela distância da região do colo até a última folha. Para a determinação da massa seca do sistema radicular (MSR, g) de cada muda, o material foi seco a $65^{\circ} \mathrm{C}$ até massa constante em estufa com circulação forçada de ar.

Todos os resultados expressos em porcentagem e em gramas foram transformados em arc seno $\sqrt{ } \mathrm{x} / 100 \mathrm{e}$ $\sqrt{\mathrm{x}}$, respectivamente, a fim de atender aos critérios de normalidade segundo teste de Lilliefors e homogeneidade de variâncias por Cochran (Banzatto \& Kronka, 2006; Ribeiro Júnior, 2012). Realizou-se análise de variância, pelo teste $\mathrm{F}$, para diagnóstico de efeito significativo (1 e $5 \%$ de probabilidade). Apenas os dados de PFR, NF, $\mathrm{S}, \mathrm{PA}$ e SR foram submetidos à análise de correlação segundo Pearson (r) ao nível de 5\% de probabilidade. As análises estatísticas foram realizadas com auxílio de planilha eletrônica e SISVAR (Ferreira, 2011).

\section{Resultados e discussão}

O efeito estatístico significativo pelo teste $\mathrm{F}(p \leq 0,01)$ quanto aos tipos de estacas foi verificado para aquelas que perderam as folhas remanescentes após redução da área foliar, sobrevivência e comprimentos de parte área e da maior raiz presente no sistema radicular. Os tipos de estacas não interagiram com as concentrações de AIB $(p>0,05)$. As concentrações estudadas de AIB não exerceram influência no desenvolvimento do sistema radicular e aéreo das mudas e, tampouco, em sua sobrevivência em casa de sombra.

As distribuições das médias e desvios padrões das variáveis avaliadas em função das concentrações de AIB foram apresentados na Figura 1. A aplicação de auxina exógena, mesmo em estacas pouco lignificadas como as herbáceas, resultou em um modesto ou nulo estímulo ao crescimento do material propagativo. Segundo Taiz \& Zeiger (2004), este evento pode ocorrer quando o nível de auxina endógena na região de alongamento se encontra próximo ao ponto ótimo para o crescimento. Da mesma forma, Faria et al. (2007) observaram a ineficiência da aplicação de auxina exógena em estacas semilenhosas de porta-enxerto de Vitis vinifera $(L$.) cv. Shiraz, levantando a possibilidade de o teor de auxina endógena nas estacas ter sido suficiente para o enraizamento.
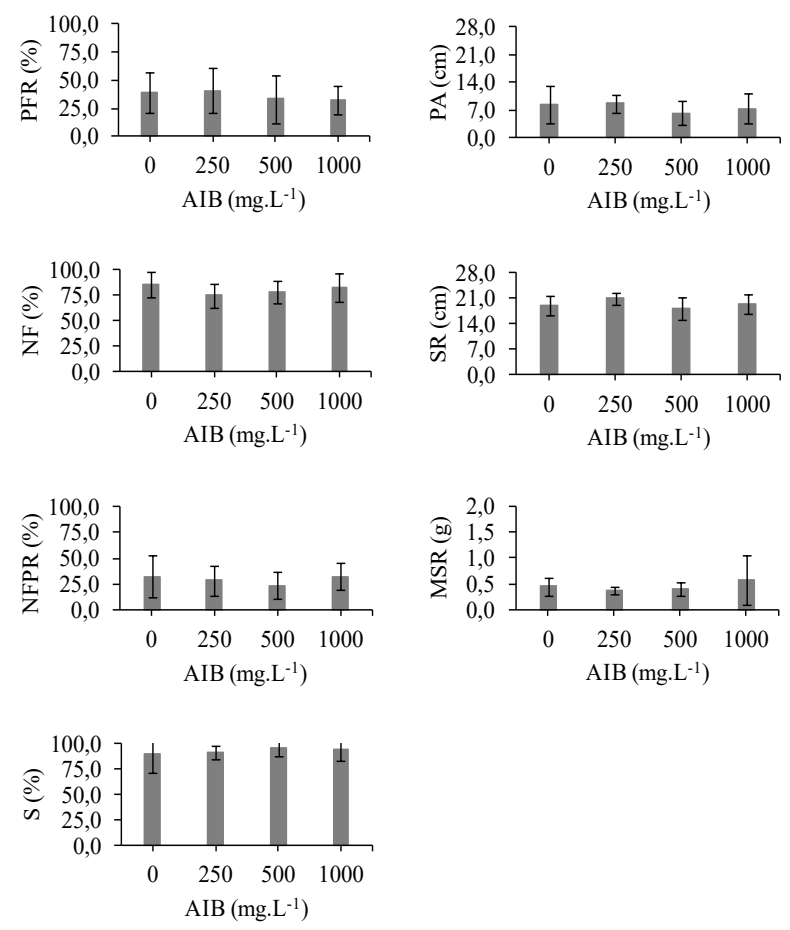

Figura 1. Média e desvio padrão das variáveis avaliadas durante a propagação vegetativa de Senna alata em função de diferentes concentrações de AIB. Variáveis avaliadas aos 42 dias (saída da casa de vegetação): $P F R=$ estacas que perderam as folhas remanescentes após redução da área foliar; NF = estacas que emitiram novas folhas e NFPR = estacas que emitiram novas folhas mesmo perdendo as remanescentes. Variáveis avaliadas aos 91dias (saída da casa de sombra): $\mathrm{S}=$ sobrevivência; $\mathrm{PA}=$ comprimento de parte aérea; $\mathrm{SR}=$ comprimento da maior raiz presente no sistema radicular e $\mathrm{MSR}=$ massa seca do sistema radicular.

Outras hipóteses que devem ser consideradas são a pouca sensibilidade do tecido à presença de auxinas (Trewavas \& Cleland, 1983) ou que as concentrações 
usadas foram muito baixas para a rápida imersão (2 s) da base das estacas em solução com AIB. Mesmo empregando o tempo de imersão de $10 \mathrm{~s}$ e três vezes mais AIB (3000 $\left.\mathrm{mg} \mathrm{L}^{-1}\right)$ que a maior concentração do presente trabalho, Neves et al. (2006) não verificaram efeito dessa auxina no comprimento da maior raiz e sobrevivência de estacas de Erythrina falcata Benth, independente da época do ano e tipo de estaca. No entanto, Gratieri-Sossella et al. (2008) concluíram que concentrações a partir de $1000 \mathrm{mg} \mathrm{L}^{-1}$ (imersão por $5 \mathrm{~s}$ ) podem reduzir a mortalidade e favorecer o enraizamento de estacas herbáceas de E. crista-galli L.

Os resultados do tratamento controle foram estatisticamente similares aos demais (T2 ao T4). Isto apresenta grande importância econômica e prática para a produção de mudas via estaquia, pois é possível manter uma elevada taxa de sobrevivência $(92,86 \pm 11,85 \%)$ e um adequado desenvolvimento vegetal mesmo na ausência de aplicação de AIB (T1), que foi o tratamento menos oneroso e laborioso ao considerar o período de instalação experimental. Esses resultados demonstram que a sobrevivência não foi comprometida pelo tempo de exposição das estacas às condições ambientais inerentes ao horário de coleta dos ramos.

As médias das variáveis avaliadas em função do tipo de estaca foram apresentadas na Tabela 1. As estacas herbáceas apresentaram maior sobrevivência e comprimentos de parte área e da maior raiz presente no sistema radicular. Somando a isso, foi o tipo de estaca que perdeu menos folhas remanescentes após redução da área foliar.

Tabela 1. Médias das variáveis avaliadas durante a propagação vegetativa de Senna alata em função de diferentes tipos de estaca.

\begin{tabular}{cccccccc}
\hline Estacas & PFR (\%) & NF (\%) & NFPR (\%) & S (\%) & PA (cm) & SR (cm) & MSR(g) \\
\hline Herbácea & $27,88 \mathrm{~b}$ & $84,19 \mathrm{a}$ & $25,66 \mathrm{a}$ & $99,44 \mathrm{a}$ & $10,34 \mathrm{a}$ & $20,62 \mathrm{a}$ & $0,44 \mathrm{a}$ \\
Semilenhosa & $44,18 \mathrm{a}$ & $77,23 \mathrm{a}$ & $33,05 \mathrm{a}$ & $86,70 \mathrm{~b}$ & $5,17 \mathrm{~b}$ & $18,04 \mathrm{~b}$ & $0,47 \mathrm{a}$ \\
\hline
\end{tabular}

Variáveis avaliadas aos 42 dias (saída da casa de vegetação): PFR = estacas que perderam as folhas remanescentes após redução da área foliar; NF = estacas que emitiram novas folhas e NFPR = estacas que emitiram novas folhas mesmo perdendo as remanescentes. Variáveis avaliadas aos 91dias (saída da casa de sombra): $\mathrm{S}=$ sobrevivência; PA = comprimento de parte aérea; $\mathrm{SR}=$ comprimento da maior raiz presente no sistema radicular e MSR = massa seca do sistema radicular. Médias seguidas na coluna por uma mesma letra não diferem significativamente entre si pelo teste $\mathrm{F}$ ao nível de $5 \%$ de probabilidade.

A emissão de novas folhas não se correlacionou significativamente com a perda daquelas remanescentes após redução da área foliar $(\mathrm{r}=0,04 ; \mathrm{p}>0,05)$. Entretanto, do ponto de vista fisiológico, a biossíntese de auxina pode ter sido retardada em função da perda de folhas remanescentes, diminuindo a razão auxina/ citocinina e favorecendo a formação de brotações. Esta afirmação se baseou na premissa que a auxina é normalmente sintetizada nos tecidos apicais da parte aérea vegetal e transportada de forma basípeta em direção ao sistema radicular (Taiz \& Zeiger, 2004).

A redução da área foliar realizada pode ter influenciado indiretamente na perda de folhas remanescentes quando as estacas foram mantidas em casa de vegetação. É importante considerar que uma redução na concentração de auxinas pode tornar as células da região de abscisão foliar sensíveis ao etileno, propiciando a queda de folhas (Taiz \& Zeiger, 2004). As estacas herbáceas responderam melhor a esse estresse mantendo mais folhas, o que, provavelmente, contribuiu para o sucesso no enraizamento e sobrevivência (Tabela 1), pois as folhas são fontes de carbono e auxina (Xavier et al.,
2013). Essas considerações podem ser comprovadas pela correlação positiva da sobrevivência com as estacas que emitiram novas folhas $(r=0,36 ; p \leq 0,05)$ e com os comprimentos da parte aérea $(\mathrm{r}=0,42 ; \mathrm{p} \leq 0,05)$ e da maior raiz presente no sistema radicular $(\mathrm{r}=0,39 ; p \leq$ $0,05)$; relação inversa foi observada para as estacas que perderam as folhas remanescentes após redução da área foliar $(r=-0,52 ; p \leq 0,05)$.

A menor frequência relativa de sobrevivência das estacas semilenhosas pode ter ocorrido em razão da maior idade ontogenética do propágulo, reduzindo o vigor fisiológico e, consequentemente, a capacidade de formar raízes (Wendling \& Xavier, 2001). Isto se deve à tendência de os ramos mais velhos acumularem inibidores de enraizamento e apresentarem menores níveis fenólicos e de auxina (Dias et al., 2012a). Além disso, o tecido lignificado pode ter atuado como barreira anatômica entre o floema e o córtex, dificultando a emissão de raízes (Xavier et al., 2013). Ressalta-se que essa tendência pode ser mais acentuada com a proximidade de estações mais frias, quando níveis de ácido abscísico (ABA) são normalmente elevados (Neves et al., 2006). 
As estacas herbáceas apresentaram maior comprimento de parte aérea, superando o tamanho das semilenhosas quando coletadas (Tabela 2). A correlação do comprimento da maior raiz presente no sistema radicular com o da parte área foi positiva $(\mathrm{r}=0,69 ; \mathrm{p} \leq$ 0,05), indicando uma possível relação de dependência entre os tecidos envolvidos. $\mathrm{O}$ intenso crescimento radicular poderia ter implicado numa elevada produção de citocinina que estimulou o crescimento da parte aérea, pois a citocinina é predominantemente sintetizada nas raízes e transportada de forma acrópeta para o ápice vegetal, estimulando a iniciação de gemas caulinares (Peres et al., 1997). Respondendo a este estímulo (feedback), as novas gemas formadas, eventualmente, garantiram o suprimento de auxina necessário para o completo desenvolvimento do sistema radicular das mudas de $S$. alata. Deste modo, a sobrevivência das estacas (caracterizada pela presença de folhas e ausência de necrose) pode ter refletido na produção de massa seca do sistema radicular de cada uma das mudas. Aos 91 dias, todas as mudas obtidas apresentaram raízes distribuídas uniformemente ao longo do tubete, sem sinais aparentes de enovelamento ou adensamento do sistema radicular (Figura 2). A espécie $S$. alata demonstrou facilidade de enraizamento e potencial para ser propagada via estaquia.

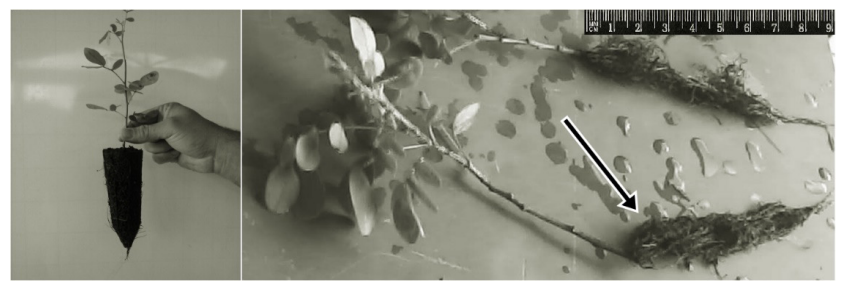

Figura 2. Muda produzida via estaquia de Senna alata com 91 dias de idade. Na imagem direita se encontra em destaque o sistema radicular fasciculado desenvolvido.

O desenvolvimento do sistema radicular envolveu a desdiferenciação de células específicas para alcançar um estado meristemático (Figura 3), sendo mostrado um primórdio de raiz reconhecível com o subsequente crescimento e emergência radicular suficiente para proporcionar a sustentação vegetal. Esta dinâmica de crescimento seguiu o padrão típico de rizogênese, conforme descrito por Xavier et al. (2013). Salienta-se que a formação de um novo meristema é essencial para a iniciação da rizogênese, sobrevivência de estacas e propagação vegetativa de mudas (Cunha et al., 2009). A distribuição das raízes com origem em um único ponto, formando um sistema fasciculado ou em cabeleira (Figura 2) está de acordo com o relatado por Xavier et al. (2013) para raízes de mudas clonais.

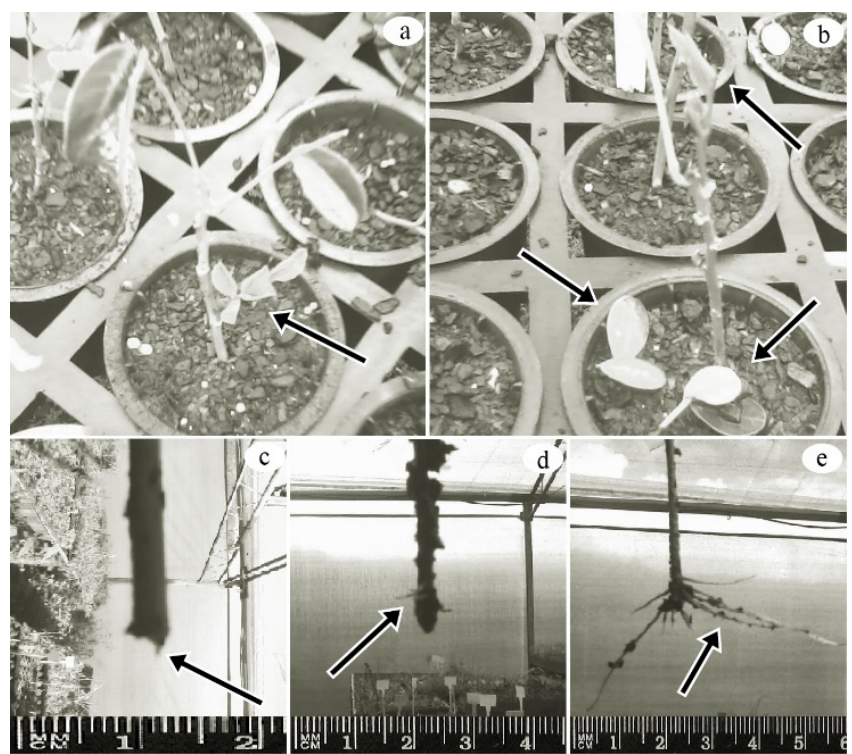

Figura 3. Estacas de Senna alata em casa de vegetação. a) estaca que emitiu novas folhas, após 10 dias; b) estaca que emitiu novas folhas mesmo perdendo as remanescentes após 10 dias; c) primórdio de raiz reconhecível após 3 dias; d) desenvolvimento do primórdio de raiz reconhecível após 14 dias e e) raiz formada em casa de vegetação após 42 dias.

Mediante o exposto, recomenda-se o uso de estacas herbáceas para a propagação vegetativa de $S$. alata, principalmente quando a disponibilidade de sementes é o fator limitante para a produção de mudas. Contudo, as concentrações estudadas de AIB não são indicadas para a propagação dessa espécie via estaquia. Os resultados obtidos fornecem subsídios relevantes para o desenvolvimento de futuras pesquisas e de protocolos que contemplem o melhoramento genético e a propagação através de estacas caulinares de espécies florestais nativas, sobretudo aquelas de ocorrência no bioma da Mata Atlântica.

\section{Conclusões}

As concentrações de ácido indol-3-butírico testadas não favorecem o enraizamento e desenvolvimento da parte aérea de estacas (com um par de folhas com dois folíolos basais) herbáceas e semilenhosas de Senna alata. No entanto, estacas de consistência herbácea ou semilenhosa de $S$. alata apresentam facilidade de enraizamento e potencial para serem propagadas. 
Mudas oriundas de estacas herbáceas de Senna alata podem apresentar maiores comprimentos de parte aérea e de raiz do que aquelas provenientes de estacas semilenhosas. As estacas herbáceas perderam menos folhas remanescentes após redução da área foliar e, consequentemente, apresentaram maior sobrevivência quando foram mantidas em casa de sombra. Assim, recomendam-se estacas herbáceas para a propagação vegetativa dessa espécie.

\section{Agradecimentos}

Ao Instituto Federal de Educação, Ciência e Tecnologia de Minas Gerais - campus São João Evangelista por todo apoio logístico e estrutural para a realização do presente trabalho.

\section{Referências}

Alfenas, A. C. et al. Clonagem e doenças do eucalipto. Viçosa, MG: Ed. da UFV, 2004. 442 p.

Alves, E. C. Clonagem por estaquia de ramos de Dovyalis hebecarpa e Dovyalis hebecarpa x D. abissinica. 2014. $33 \mathrm{f}$. Dissertação (Mestrado em Agronomia) - Universidade Estadual Paulista, Jaboticabal, SP.

Amaral, G. C. et al. Produção de mudas de Duranta repens L. pelo processo de estaquia. Revista de Ciências Agrárias, v. 35, n. 1, p. 134-142, 2012.

Augusto, C. S. S. et al. Enraizamento e aclimatização de plantas micropropagadas de amoreira-preta cv. Brazos. Revista Brasileira de Fruticultura, v. 28, n. 3, p. 473-476, 2006. DOI: 10.1590/S010029452006000300029.

Banzatto, D. A. \& Kronka, S. N. Experimentação agrícola. 4. ed. Jaboticabal, SP: Funep, 2006. 237 p.

Braga, F. A. et al. Características ambientais determinantes da capacidade produtiva de sítios cultivados com eucalipto. Revista Brasileira de Ciência do Solo, v. 23, n. 2, p. 291-298, 1999. DOI: 10.1590/S0100-06831999000200013.

Braga, L. F. et al. Escarificação ácida, temperatura e luz no processo germinativo de sementes de Senna alata (L.) Roxb. Revista Brasileira de Plantas Medicinais, v. 12, n. 1, p. 1-7, 2010. DOI: 10.1590/S1516-05722010000100001.

Conover, C. A. \& Poole, R. T. Storage time and temperature affect growth of Dracaena fragans 'Massangeana'. Proceedings of the Florida State Horticultural Society, v. 104, p. 331-333, 1991.

Correia, A. C. G. et al. Redução foliar em miniestacas e microestacas de clones híbridos de Eucalyptus globulus. Revista Árvore, v. 39, n. 2, p. 295-304, 2015. DOI: 10.1590/0100-67622015000200009.

Cunha, A. C. M. C. M. Papel da nutrição mineral na formação de raízes adventícias em plantas lenhosas. Pesquisa Florestal Brasileira, n. 58, p. 35-47, 2009. DOI: 10.4336/2009.pbf.58.35.
Dias, P. C. et al. Estaquia e miniestaquia de espécies florestais lenhosas do Brasil. Pesquisa Florestal Brasileira, v. 32, n. 72, p. 453-462, 2012a. DOI: 10.4336/2012.pfb.32.72.453.

Dias, P. C. et al. Propagação vegetativa de progênies de meios-irmãos de angico-vermelho (Anadenanthera macrocarpa (Benth) Brenan) por miniestaquia. Revista Árvore, v. 36, n. 3, p. 389-399, 2012 b. DOI: 10.1590/S0100-67622012000300001.

Dias, P. C. et al. Resgate vegetativo de árvores de Anadenanthera macrocarpa. Cerne, v. 21, n. 1, p. 83-89, 2015. DOI: $10.1590 / 01047760201521011381$.

Faria, A. P. et al. Enraizamento de estacas semilenhosas do portaenxerto de videira 'IAC-Jales' tratadas com diferentes concentrações de ácido indolbutírico. Semina: Ciências Agrárias, v. 28, n. 3, p. 393-398, 2007. DOI: 10.5433/1679-0359.2007v28n3p393.

Faria, J. C. T. Uso de resíduos orgânicos na produção de mudas de Senna alata (L.) Roxb. Ecologia e Nutrição Florestal, v. 1, n. 3, p. 133-146, 2013. DOI: 10.13086/2316-980x.v01n03a05.

Ferreira, D. F. SISVAR: a computer analysis system. Ciência e Agrotecnologia, v. 35, n. 6, p. 1039-1042, 2011. DOI: 10.1590/ S1413-70542011000600001.

Gratieri-Sossella, A. G. et al. Propagação da corticeira do banhado (Erythrina crista-galli L.) (Fabaceae) pelo processo de estaquia. Revista Árvore, v. 32, n. 1, p. 163-171, 2008. DOI: 10.1590/S010067622008000100018.

Medeiros, E. V. et al. Extrato etanólico de Senna alata no controle de Fusarium oxysporum, causador da murcha-de-fusarium no meloeiro. Revista Brasileira de Engenharia Agrícola e Ambiental, v. 16, n. 11, p. 1166-1170, 2012. DOI: 10.1590/S1415-43662012001100004.

Mindêllo Neto, U. R. Efeito do ácido indolbutírico no enraizamento de estacas herbáceas de dois porta-enxertos de pessegueiro. Revista Brasileira de Agrociência, v. 10, n. 4, p. 433-437, 2004. DOI: 10.18539/cast.v10i4.999.

Moraes, C. E. et al. Influência das folhas no enraizamento de miniestacas de híbridos de eucalipto. Nucleus, v. 11, n.1, p. 101-106, 2014. DOI: $10.3738 / 1982.2278 .995$.

Neves, T. S. et al. Enraizamento de corticeira-da-serra em função do tipo de estaca e variações sazonais. Pesquisa Agropecuária Brasileira, Brasília, v. 41, n. 12, p. 1699-1705, 2006. DOI: 10.1590/ S0100-204X2006001200003.

Ogunjobi, A. A. \& Abiala, M. A. Antrimicrobial activity of Senna alata and Phyllanthus amarus. Global Journal of Pharmacology, v. 7, n. 2, p. 198-202, 2013. DOI: 10.5829/idosi.gjp.2013.7.2.74179.

Pathak, M. L. \& Chhetri, D. B. Senna alata (Linnaeus) Roxburgh (Leguminosae), a new addition to the flora of Nepal. Bulletin of Department of Plant Resources, n. 37, p. 21-22, 2015.

Peña, M. L. P. et al. Concentrações e formas de aplicação do ácido indolbutírico na propagação por estaquia dos mirtileiros cvs. Flórida Clímax. Semina: Ciências Agrárias, v. 33, n. 1, p. 57-64, 2012. DOI: 10.5433/1679-0359.2012v33n1p57.

Peres, L. E. P. et al. Níveis endógenos de AIA, citocinina e ABA em uma orquídea acaule e uma bromélias sem raiz, determinados por HPLC e ELISA. Revista Brasileira de Fisiologia Vegetal, v, 9, n. 3, p. 169-176, 1997. 
Pio, R. et al. Enraizamento de estacas lenhosas dos marmeleiros 'Portugal' e 'Japones' tratadas com ácido indolbutírico. Revista Ceres, v. 51, n. 298, p. 777-786, 2004.

Pio, R. et al. Propagação de estacas apicais de figueira: diferentes ambientes, ácido indolbutírico e tipo de estaca. Ciência e Agrotecnologia, v. 30, n. 5, p. 1021-1026, 2006. DOI: 10.1590/ S1413-70542006000500030.

Purcino, M. et al. Efeito das folhas no enraizamento de estacas de alfavaca-cravo e alfavaca-anis. Revista de Ciências Agroveterinárias, v. 11, n. 2, p. 93-98, 2012.

Quisen, R. C. \& Angelo, P. C. S. Manual de procedimentos do laboratório de cultura de tecidos da Embrapa Amazônia Ocidental. Manaus, AM: Embrapa Amazônia Ocidental, 2008. 44 p. (Embrapa Amazônia Ocidental. Documentos, 61).

Ribeiro Júnior, J. I. Métodos estatísticos aplicados à melhoria da qualidade. Viçosa, MG: Ed. da UFV, 2012. 385 p.

Rodrigues, I. M. C. et al. Estudo fitoquímico de Senna alata por duas metodologias. Planta Daninha, v. 27, n. 3, p. 507-513, 2009. DOI: 10.1590/S0100-83582009000300011.

Santos, L. W. et al. Propagação vegetativa de mulungu (Erythrina velutina Willd. - Fabaceae). Revista Brasileira de Ciências Agrárias, v. 9, n. 3, p. 420-426, 2014. DOI: 10.5039/agraria. v9i3a4062.

Sarmiento, A. I. P. et al. Estaquia de Ficus cestrifolia Schott ex Spreng.: concentrações de ácido indol-3-butírico e ambientes de enraizamento. Iheringia Série Botânica, v. 70, n. 1, p. 167-172, 2015.
Stuepp, C. A. et al. Presença de folhas e ácido indol butírico no enraizamento de estacas de quiri. Comunicata Scientiae, v. 6, n. 2, p. 181-193, 2015.

Taiz, L. \& Zeiger, E. Fisiologia Vegetal. 3. ed. Porto Alegre: Artmed, 2004. 719 p.

Tofanelli, M. B. D. et al. Método de aplicação de ácido indolbutírico no enraizamento de estacas herbáceas de pessegueiro. Revista Brasileira de Fruticultura, v. 25, n. 2, p. 363-364, 2003. DOI: 10.1590/S0100-29452003000200049.

Trewavas, A. J. \& Cleland, R. E. Is plant development regulated by changes and the concentration of growth substances or by changes in the sensitivity to growth substances? Trends in Biochemical Sciences, v. 8, p. 354-357, 1983. DOI: 10.1016/0968-0004(83)903596.

Vilarinho, M. K. C. \& Cândido, A. K. A. A. Efeito de biorregulador no enraizamento de estacas de eritrina-verde-amarela (Erythrina indica picta). Revista Agrarian, v. 7, n. 24, p. 251-256, 2014.

Wendling, I. \& Xavier, A. Gradiente de maturação e rejuvenescimento aplicado em espécies florestais. Floresta e Ambiente, v. 8, n. 1, p. 187-194, 2001

Xavier, A. et al. Enraizamento de miniestaca caulinar e foliar na propagação vegetativa de cedro-rosa (Cedrela fissilis Vell.). Revista Árvore, v. 27, n. 3, p. 351-356, 2003. DOI: 10.1590/S010067622003000300011.

Xavier, A. et al. Silvicultura clonal: princípios e técnicas. 2. ed. Viçosa, MG: Ed. da UFV, 2013. 279 p.

Zem, L. M. et al. Estaquia caulinar herbácea e semilenhosa de Drimys brasiliensis. Revista Ciência Agronômica, v. 46, n. 2, p. 396-403, 2015. DOI: 10.5935/1806-6690.20150019. 